\title{
O monismo complexificado de Schelling
}

\author{
Schellings complexified monism
}

\author{
Humberto Schubert Coelho \\ humbertoschubert@yahoo.com.br \\ (Universidade Federal de Juiz de Fora, Minas Gerais, Brasil)
}

\begin{abstract}
Resumo: Apresentaremos diferenças técnicas que ajudam a compreender e justificar a passagem de um modelo de monismo forte, no sistema da identidade de Schelling, a um monismo complexificado e de inspiração böhmiana na fase da Filosofia e Religião e dos Escritos sobre a liberdade. Como o segundo modelo inclui em si uma dimensão processual e conflitiva mais complexa, ele tem a vantagem de acomodar um conceito substantivo e concreto de liberdade no sentido almejado por Schelling, um poder capaz de fomentar o bem e o mal. Para que isso seja possível, contudo, é necessário que a moralidade e toda a diferença em geral sejam assumidas seriamente no novo esquema conceitual, pois a homogeneização de aparência espinosana tendia a tornar ilusórias as diferenças.
\end{abstract}

Palavras-chave: monismo; Deus; liberdade; conflito; integração.
Abstract: This paper presents a set of technicalities in order to understand and justify Schelling's transition from a strong model of monism in his System of Identity to a more complex and dynamical one in his Philosophy and Religion and Freiheitschrift, both already under Boehmian inspiration. Since the second model includes a more complex processual and conflictive dimension, it has the advantage of accommodating a more concrete and substantive concept of freedom in the sense meant by Schelling, which is a power to foment good and evil. This demands, however, that morality and any difference in general are seriously assumed in the new conceptual framework, because a homogenization in a fashion similar to the Spinozan disqualified differences as illusive.

Keywords: monism; God; freedom; conflict; integration.

DOI: http://dx.doi.org/10.11606/issn.2318-9800.v23i1p13-26

"Natureza em si, ou eterna natureza, é apenas o espírito nascido na objetividade, a essência de Deus introduzida na forma" (Schelling, 1997, I, 2, p. 66).

\section{Introdução}

No oceano da obra e do pensamento de Schelling, muitas correntezas contraditórias entre si estão acomodadas sob uma visão total. Sua filosofia pretende acomodar e subsumir ao menos três grandes e muito particulares correntes de pensamento. Ela quer englobar uma perspectiva natural, escapando do viés subjetivista de que a filosofia de Fichte é suspeita; crítica, distanciando-se reflexivamente e com 
atitude fiscalizadora, na tradição de Kant; e cristã, assumindo que a essência última de tudo é espiritual e moral, evitando, com isso, a recaída em um monismo "morto". Esse projeto integrador algo megalomaníaco foi intentado não apenas filosoficamente por Schelling e Hegel, mas também artisticamente por Goethe, enquanto versões em que duas ou mesmo uma destas correntes reduzem a(s) outra(s) também proliferaram rapidamente.

O próprio autor não nos permite esquecer que a sua filosofia é o desdobramento de pressupostos parcialmente velados e inexplorados de um kantismo iluminado por Fichte. Quanto a Espinosa, influência igualmente primária na construção de todo o pensamento schellinguiano, as referências também abundam. ${ }^{1}$ Enquanto o diálogo com Kant e Espinosa se evidencia entre a fase fichteana e a fase da filosofia da identidade, a exploração do conceito de Deus no Schelling maduro não prescinde de uma maior explicitação do elemento böhmiano de sua meditação.

Schelling tampouco é original nessa mistura. Goethe, Baader, Eschenmayer e o próprio Hegel se relacionam abertamente com Kant, Espinosa e Böhme, ainda que extraindo matizes distintos da relação entre eles e ainda muitas outras fontes de influência. Ao passo que o debate sobre Kant e Espinosa já se desenvolve rapidamente desde a primeira metade da década de 1790, a importância de Böhme cresceu durante e por causa dos desdobramentos do romantismo e do idealismo nascentes.

A presença böhmiana se fazia já sentir pela substituição do jargão técnico e claro do Iluminismo por metáforas líricas de ares joaninos, agostinianos ou neoplatônicos, especialmente em autores que incluíam a religião entre seus interesses principais.

$O$ período é marcado pela dialética fina entre a filosofia transcendental de Kant e o sentimentalismo romântico. Na arte e na ciência grandes revoluções inauguravam as noções de criatividade e temporalização dos fenômenos e da própria mente, chegando-se, na expressão de Schelling, à identificação entre arte, ciência e religião em uma visão de mundo onde a natureza seria a "poesia da mente" (Richards, 2002, p. 470).

Seja qual for o grau de sua influência, “Espinosa jamais teria dito 'sentimento é tudo'. Não foi por nada que ele expressou o amor a Deus como amor intelectual

1 Espinosa passa a ser tema indissociável do pensamento schellinguiano já nas Cartas sobre o dogmatismo e o criticismo. Interessado no modelo integrativo de uma metafísica da totalidade, pelo que se interessa por Platão, pelo neoplatonismo e por Espinosa, Schelling está, contudo, comprometido com o modelo estritamente crítico e transcendental dessa unidade fundamental na esteira de Reinhold e Fichte, isto é, ao modo permitido por Kant, ainda que de um modo posteriormente entendido como certa torção deste. Referências relevantes são Timm, H. Gott und die Freiheit: Studien zur Religionsphilosophie der Goethezeit, Bd. 1, Die Spinozarenaissance; Otto, R. Studien zur Spinozarezeption in Deutschland 18. Jahrhundert. Nessas obras se mostra a forma peculiar segundo a qual Espinosa é recebido, muitas vezes mediado por um vitalismo e sentimentalismo rousseauniano, outras por uma abordagem teológica que guarda ligação com Lessing ou com a mística alemã, e que reconfiguram o panteísmo de Espinosa sob moldes mais palatáveis à preocupação teológica cristã e a uma metafísica da liberdade. 
de Deus” (Copplestone, 1946, p. 45). Em geral, e resumidamente, o panteísmo dos românticos apresenta um modelo estruturalmente espinosano, mas preenchido, não com a plácida contemplação matemática da lógica cósmica, e sim com os fortes sentimentos de Rousseau e a noção kantiana de um sujeito do conhecimento e da ação espontâneos. Schelling, como os demais idealistas e românticos, preferia sempre falar de uma anima mundi, não de um Todo imóvel.

\section{A presença e o aspecto do semimonismo de Böhme}

O Kant e o Espinosa de Schelling nunca foram fiéis aos originais, moldando-se à visão criativa e muito própria do autor. Isso porque muitos outros autores hoje tidos como secundários, como Goethe, Schiller, Herder, Schulze, Jacobi ou Reinhold, eram influências fortes para todos os pensadores alemães da década de 1790 , de modo que as leituras e respectivas recepções dos grandes clássicos eram sempre muito mediadas por discussões levantadas por um amplo e diversificado debate coletivo.

Conscientes de adaptar Espinosa aos interesses teológicos, estéticos e morais de seu ambiente, os alemães do final do século XVIII, a exemplo de Goethe, tinham por ele uma veneração distanciada e crítica. Similarmente, admiradores de Espinosa ou do neoplatonismo estavam dispostos a "corrigir" Kant para que uma metafísica francamente integrativa pudesse surgir (Richards, 2002; Coelho, 2012), contrapondose de certo modo àqueles que prefeririam manter o legado kantiano mais fiel a seu projeto crítico. Por isso, não é de espantar que a hierarquia forte e depreciativa de Fichte entre um Eu plenipotente e uma natureza submissa, posta como "palco" da ação do Eu, soasse como reducionismo ilegítimo aos olhos de Schelling. 0 admirador de Fichte logo sairia de sob suas asas em busca do calor e da luz de sua visão original de um mundo e uma natureza preenchidos por Deus.

Jakob Böhme não era desconhecido da teologia alemã, mas ressurgiu em uma pequena renascença por intermédio de Friedrich Oetinger e Franz Baader. 0 primeiro teve fundamental importância no resgate da obra de Böhme, produzindo para sua seleção um prefácio bastante impactante na época. Nesse texto, Oetinger definiu o pensamento de Böhme como voluntarista, transformando a noção luterana original da primazia da fé em uma rica psicologia ou metafísica da vontade. Nas palavras de Oetinger,

A fé não é um convencimento quanto à palavra de Deus, mas um engajamento. Fé é colocar-se a serviço de Jesus Cristo, ela forma a nossa alma com fundamento em Jesus Cristo. Na fé, como em todo o cristianismo, há dois acontecimentos: o desprezo do mundo, e a união com Deus em Cristo (Böhme, 1923, p. 70).

Estes ares pietistas indubitavelmente têm ligação com o voluntarismo de Böhme.

Em seu aspecto mais metafísico, o pensamento de Böhme ia no sentido de um 
proto-idealismo objetivo, em que a vontade real (de Deus) cria o mundo a partir de um anseio por agir e interagir. A fonte processual se contrapõe à noção metafísica de substância, e acomoda sob novas luzes o finito e o infinito. $O$ resultado é um princípio de identidade cuja dinâmica processual dista muito da de Espinosa. "Ela (a alma) é como um olho de fogo, surgida em igualdade com o primeiro princípio" (Böhme, 1923, p. 299).

Na sagaz percepção de Hans L. Martensen, é impossível querer, odiar ou amar um nada, ou algo amorfo. "Nenhum ato da vontade é possível sem imaginação. Uma vontade deve ter um objeto; mas um objeto posto pela vontade jaz no futuro, deve ser elaborado na imaginação. Uma vontade se determina por motivos... coisas imaginárias" (Martensen, 1885, p. 64). Embora Martensen já esteja sob influência do idealismo, a ideia de que o objeto da vontade pode desdobrar-se reflexivamente dela mesma estava, sim, implícita em Böhme, o que fez de seu redescobrimento em fins do século XVIII um evento promissor diante do problema presente de conciliar a lógica da reflexão, vista por alguns pensadores como a essência formal do idealismo transcendental e uma processualidade da liberdade, ainda muito implícita e carente de desenvolvimento, mas já insinuada como conteúdo daquele mesmo idealismo transcendental.

A conciliação proposta pelo teosofista integra, mas não identifica. Böhme é um holista, mas não um panteísta (Baader, 1855, pp. 37-40), e se em algum sentido ele é um monista, já não se trata de um monismo monótono e isento de conflitos e reviravoltas. "Deus é o espírito do mundo, o mundo é o organismo de Deus" (idem, p. 20). A cisão entre o Deus-liberdade e o fundo obscuro do qual emerge o mal, e a diferença concreta (não aparente) entre os entes, que permite a um desejar o outro, o confronto entre vontades individuais e seu relacionamento com um Deus espiritual e ativo (não abstrato) fazem com que a conciliação monista tradicional perca plausibilidade.

Isso não quer dizer, por outro lado, que Böhme recaia em um pluralismo stricto sensu. A imanência é tão enfatizada quanto em qualquer monismo, mas agora precisa sair de si e se encontrar, já não em outra "forma" ou "modo", mas sim numa outra vontade em si mesma essente.

De modo quase espinosano, para Böhme o egoísmo é uma ebriedade da consciência (da alma) com sua própria força interna. É o contato do intelecto com a vontade, e a descoberta de que minha vontade é a fonte de sentido dos meus próprios atos que me faz amar orgulhosamente meu próprio poder. Ora, a vontade é fonte do ser; assim como a vontade elege os fins ela precisa instrumentalizar pelo intelecto os meios e discernir adequadamente os próprios objetos de seus propósitos. Raciocinando sobre o que lhe apraz, a vontade se desdobra em livre-arbítrio. Por isso diz Böhme: 
Mas que Deus queira tornar uma de suas vontades obstinada, e fazer treva a partir de seu próprio projeto, isto não é verdade. Deus não enfeitiça ninguém: o homem tem uma vontade livre. Ele apega-se ao que quer; mas ele será tomado por um dos dois, Céu ou Inferno, e naquele para o qual ele se dirigir, aí estará (Böhme, 1842, IV, pp. 20; 72).

O intelecto só mostra à vontade o que ela poderia empreender, e a faz ansiar, este é o seu papel. Por si ele não possui nenhuma força transformadora. Ele é a forma, a organização. A vontade é o conteúdo que preenche os objetos dados no anseio. 0 anseio é o caminho do mundo para a vontade, a forma como o espírito recebe os demais elementos do mundo, do ponto de vista da divisão que the é própria. Pode ser preenchido pelos sentidos, pela memória, pela inclinação das paixões ou pelo intelecto. Tudo que afeta a vontade é anseio, e o homem só não tem anseio em relação àquilo que ignora ou despreza. A medida do anseio é a afeição, o gosto, a significação que algo possui para o indivíduo. Daí o dever ser vigiado e dominado, para que a alma não se disperse de si mesma e de seus propósitos espirituais, alienando a vontade numa escravidão entre os particulares. A vontade em atividade é ação, e uma vez que tenha optado por um determinado anseio entre outros, somente outra vontade, individual ou da Providência, pode detê-la. A ética (ou ético-metafísica) de Böhme prescreve, desta forma: "O homem é o princípio primeiro de suas próprias ações” (Boutroux, 1908, p. 276).

Essa defesa forte e surpreendente do livre-arbítrio na tradição luterana ainda nascente não significa que a fé, outra dimensão volitiva, seja igualmente transposta ao patrimônio humano.

Fé não é outra coisa senão unir a sua vontade a Deus, e admitir a palavra e a força de Deus na sua própria vontade, de modo que estes dois se tornem, enquanto vontade divina e vontade humana, uma substância e um ser, que a vontade do homem tornese vontade de Deus: Ora, assim conta-se por direito o Cristo em seu sofrimento, martírio, morte e ressurreição em sua própria humanidade... (Böhme, 1923, p. 366).

E também assim se insinuam no discurso racional outros mistérios fundamentais do cristianismo, como a promessa de nos tornarmos unos com Cristo na fé. Destarte:

A alma é um olho no seu eterno incriado. Um símile da eternidade. Uma figura e imagem do primeiro princípio e igual ao Pai em suas três pessoas... Então o Verbum Domini colocou a alma junto ao eterno Fiat na eterna vontade do Pai, no centro da eterna natureza e aberta ao Espírito Santo, mas como um fogo, que jaz na eternidade... (idem, p. 298).

Ora, Deus é tudo ou é um outro que gera o ser como um pai? A julgar pela interpretação de Baader sobre o pensamento de Böhme, Deus é o centro onipresente de todas as coisas (panteísmo) e igualmente um outro que precede e se coloca acima de todas as coisas (teísmo) (Baader, 1855, pp. 168-169). Nem panteísmo nem dualismo. Deus é o outro que está em tudo: panenteísmo. Também Boutroux advoga a 
necessidade de ruptura com os esquemas tradicionais em favor de um panenteísmo. “O problema está, em Böhme, em derivar a matéria do espírito, sem cair no teísmo, e de fundar a natureza sensível na natureza divina sem cair no panteísmo" (Boutroux, 1908, p. 261). Deus é Deus mesmo, e não se confunde com os entes, sequer com o ser, mas ele também não se aparta do ser, e ele e o ser não se estranham. Há diferença, mas a diferença não chega a criar uma ruptura, dando antes espaço a um jogo dialético e orgânico, ou um relacionamento interpessoal.

Em sintonia com Goethe e sob influência de Baader, Schelling também haure estímulo de sua amizade e confrontação com Karl Eschenmayer, o qual ataca seu sistema de 1798-1802 com base em uma defesa da incognoscibilidade última de Deus. Em reação ao fideísmo de Eschenmayer, Schelling replica em 1804, através de seu escrito Filosofia e Religião, que a fé não pode ensejar conhecimento, e que um Absoluto pensável cientificamente deve ser um Absoluto passível de acomodação no horizonte de trabalho da razão (Eschenmayer, 2016, XX).

Em Eschenmayer, por outro lado, se vislumbra um elemento que seria considerado na meditação de Schelling a partir da Freiheitsschrift: ${ }^{2}$

A especulação filosófica não pode penetrar o divino, já que este não é redutível a conceitos e ideias. O divino, assim, se separa do Absoluto e só pode ser aproximado através da fé e da revelação, mas nunca tangenciado. Mesmo o Absoluto não pode ser apreendido em sua inteireza através da razão e da especulação. Pois, se pudesse ser definido por ideias e conceitos, não seria mais Absoluto algum (Eschenmayer, 2016, $\mathrm{XXI}){ }^{3}$

Restaria apenas, para Eschenmayer, a alma harmônica com a anima mundi a tarefa de acessar a unidade suprema. Schelling vai reconsiderar sob outra perspectiva a observação de Eschenmayer, pois ele não quer segui-lo na diferenciação exagerada entre essência e existência. Mas, a partir dos ataques de Hegel na Fenomenologia do Espirito, Schelling também não podia manter aberto o flanco que the permitia ser acusado de homogeneizar forçadamente os particulares e as diferenças no todo.

Por isso, Schelling permite que a nomenclatura de cunho científico dos escritos anteriores comece a migrar por volta do ano de 1800 em direção à nomenclatura böhmiana, a qual tem a vantagem de manter um pano de fundo monista ou panteísta incluindo também conceitos centrais para o cristianismo como criação, o "fundo" da vontade, o embate entre luz e trevas, o nascimento e o renascimento do espírito, a "Imagem" do Criador e a "imagem" na mente da criatura, e uma visão mais conflitiva

\footnotetext{
2 Abreviação comumente usada para o livro Investigações filosóficas sobre a essência da liberdade humana e os assuntos a ela relacionados.

3 Embora contrário ao tom muitas vezes místico de Eschenmayer, Schelling passa a incluir efetivamente em sua visão de Deus um elemento sempre mais incondicionado e inefável, pelo que terá necessidade de utilizar uma linguagem böhmiana do mistério ou silêncio que permite o surgimento do que é discernível e perceptível. Sem querer abandonar o discurso racional sobre o ser, reconhecerá que Deus é também o "Senhor do ser".
} 
e menos harmônica da relação entre o espiritual e o material, correspondentes a uma dialética entre "Centro e Periferia". ${ }^{4}$

Só após nos acercarmos dessas razões entendemos como Schelling pode acolher tão favoravelmente em seu sistema, até então marcado por pretensões de saber científico e sistemático, sentenças como a seguinte:

Como a alma é essencial e é em seu próprio ser um anseio, é conhecido que ela deve se dividir em dois Fiat: um patrimônio corpóreo, e o outro é um princípio da vontade de Deus, onde Deus anseia em sua figura, assim o anseio de Deus é como um Fiat na alma = centro e cria a partir daí a vontade da alma sob o coração de Deus (Böhme, 1923, p. 300).

Por outro lado, contudo, há fragmentos de Böhme, especialmente em Aurora, que tornam esse acomodamento mais fácil e harmônico com o monismo espinosano:

Onde todo o ser não é Deus, tu não és imagem de Deus; onde quer que haja um Deus estranho, tu não tens parte nele. Portanto tu és criado a partir deste Deus e vives nele mesmo, [...] e se tu morres, então tu serás enterrado neste Deus. Onde houver, então, um Deus distinto deste, que esteja fora deste, então quem te fará novamente vivo, tu que vives amputado de Deus... Se o teu corpo não for da mesma essência de Deus, então deve haver dois tipos de divindade, o teu corpo pertence ao Deus do mundo, e o teu coração pertence ao Deus desconhecido. Ó, abre os olhos da alma homem-criança... quando tu vês as profundezas, as estrelas, e a terra, aí tu vês o teu Deus, e neste mesmo Deus tu és e vives, e o mesmo Deus te rege, e a partir do mesmo Deus tu tens os teus sentidos, e és uma criatura oriunda dele e dentro dele, do contrário não serias nada... Assim eu não escrevo de maneira pagã, mas filosófica; e não sou, portanto, um pagão, mas eu tenho o profundo e verdadeiro conhecimento do grande Deus único, que é tudo (Böhme, 1923, pp. 196-197).

Em textos como este, Schelling vê conciliados o monismo, de origem platônica ou espinosana, e a noção tipicamente cristã do relacionamento pessoal, o que the propicia integrar esses elementos em um novo processo, superior e mais inclusivo.

Será também relevante, contudo, relembrarmos os elementos, por assim dizer, pré-böhmianos da filosofia de Schelling, para só então partirmos para uma análise do lugar desta influência na filosofia e teologia do Schelling maduro.

\section{A condição conceitual prévia para a recepção böhmiana}

Poder-se-ia perguntar por que Schelling não retorna ao lugar seguro do monismo espinosano, onde praticamente todos os problemas ontológicos mais sérios estavam resolvidos, ao menos aos olhos dos entusiastas de Espinosa. Não teria bastado melhorar e corrigir o panteísmo acrescentando-lhe uma dimensão sentimental e poética, como fez Goethe? (Hoffmann, 2001) A razão para a resposta negativa, querse observar aqui, não está apenas no gosto de Schelling para a espiritualidade e o

4 Para exemplos de fragmentos com forte presença desses elementos: (Schelling, 1997, I, 7, pp. 361; 363-367). 
lirismo cristãos, mas repousa sobre fundamento mais objetivo, embora este só vá se revelar plenamente na filosofia positiva. Já em Religião e Filosofia e nas Investigações filosóficas sobre a essência da liberdade humana, Schelling demonstrara reverência intelectual pelo poder da metáfora, empregando particularmente as metáforas böhmianas de modo insistente. Ele passou a acreditar que a metáfora, quando bem construída e psiquicamente efetiva, isto é, identificada como uma alegoria que faz referência competente a processos da realidade, é uma expressão de experiências ou "visões" arquetípicas, que ultimamente representam o progressivo revelar-se concreto de Deus (Hayner, 1967; Dantz \& Jantzen, 2011). ${ }^{5}$ Logo, o mito e a revelação profética, mesmo a poesia em seu caráter mitopoiético, deveriam ser entendidos como parte do mundo, a ser integrada na compreensão filosófica integrativa do Absoluto. Muito mais que um "detalhe cultural” ou preferência pessoal, portanto, os esquemas metafóricos centrais da cultura passaram a representar, para Schelling, uma dimensão da verdade. ${ }^{6}$

Que $A$ = A é a sentença primordial, para a qual nenhuma demonstração é necessária, já havia sido explicitado na dedução de Fichte e na do próprio Schelling em seus escritos Acerca do Eu como princípio da filosofia e $O$ incondicionado no conhecimento humano. Lá se deduzira a diferença a partir da unidade primária do Eu, e no desenvolvimento posterior da filosofia da identidade, Schelling reviu exaustivamente essa exposição até que pudesse afirmar satisfatoriamente que todo o particular e a dinâmica pertinente a ele remontariam a uma identidade absoluta entre Subjetivo e Objetivo conforme o princípio $A=A$. Com grande perspicácia, Schelling observa que o saber sobre a identidade se evidencia na estruturação racional, comum aos mundos da natureza e da subjetividade, e que, aliás, o saber já é um objeto da razão onde a oposição dialética sujeito-objeto pode ser constatada, mas numa instância contemplativa da razão enquanto tal uma identidade original poderia ser vislumbrada, intuída diretamente pela consciência. “A identidade é o ser pertencente à razão, o objeto predizível, através do qual ela é pronunciável. Uma vez pronunciada, ela se torna a lei suprema" (Zantwijk, 2000, p. 83).

No Primeiro projeto de um sistema da filosofia da natureza, Schelling explicita a pergunta já semeada em seus escritos anteriores: o infinito do mundo físico e a infinitude essencial do espírito não sugerem uma conexão entre os dois? ${ }^{7}$ Falar de uma identidade absoluta e originária é insinuar que a fórmula $A=A$ pode ser gênese de $A=B$. A essência é a forma, o sujeito é o objeto. Nem um nem outro, nem a soma de ambos, mas a duplicidade do ser como identidade absoluta dos dois. A identidade,

\footnotetext{
5 Cabe também observar que a metáfora tem papel conciliatório na filosofia da identidade devido a seu poder de sintetizar em si o conhecimento racional e a intuição intelectual. Com isso, a arte teria lugar privilegiado no sistema filosófico, viabilizando a reconciliação concreta entre ideal e real.

6 Não por acaso exatamente como Goethe (Coelho, 2012, pp. 151-170).

7 Ele o diz quase nessas palavras em Schelling, 1997, I, 3, p. 16.
} 
para Schelling, exprime racionalmente intuições místicas e filosóficas (En kai Pan) menos exatamente deduzidas ou menos fundamentadas, por isso ele se desgosta do idealismo subjetivo, para o qual o Eu é o absoluto e o natural deriva do Eu. Ele busca a identidade original tal que sujeito e objeto sejam suas facetas. Mas nisso receberá a dura crítica de Hegel quanto à falta de consistência e efetividade dos particulares e das diferenças (Vetö, 1998, pp. 26-28).

Schelling começara por trazer dinamicidade e processualidade fichteana ao seu primeiro monismo. Ele já não vê uma substância com duas faces, mas dois polos de um organismo. A dualidade é mais justificável quando o contraste e a diferença servem ao propósito de estimularem-se reciprocamente, produzindo movimento e diversidade. Como a dualidade, contudo, remonta à identidade, a mesma intuição intelectual com que o Eu se apreende como liberdade é transformada no poder superior da razão de vislumbrar a unidade total na identidade entre sujeito e objeto. Então, a intuição intelectual reconhece o sujeito na natureza, que é tão somente o modo inconsciente dessa mesma essência, ao passo que a natureza também contém em si a lógica da reflexão, já não subjetiva, mas objetiva, isto é, como capacidade de extrair de si seres cada vez mais espirituais, mais livres. Enquanto o homem marcha para dentro com auxílio do exterior, a natureza marcha para fora com auxílio do interior. Aquele reflete sua inteligência no mundo e retorna como consciência; esta busca objetivar novas formas a partir de sua crise interna entre o princípio espiritual e o seu ser material. Não só duas formas de ver o mesmo, como duas formas de ser do mesmo.

No Sistema do Idealismo Transcendental, ele diz:

O objetivo final, tornar-se objeto, a natureza só atinge por sua última e suprema reflexão, que não é senão o homem, ou, genericamente, o que chamamos razão, pela qual a natureza retorna a si completamente, e pela qual se revela que a natureza é originalmente idêntica ao que em nós é conhecido como inteligente e consciente (Schelling, 1997, I, 3, p. 341).

A ação é o objetivar-se do ser, e o ser de natureza é aquele que, por escassez de liberdade, só pode objetivar-se como espacialidade. Ainda assim, o objeto se afirma como autossubsistente, o mesmo princípio que no Eu tem forma plena. Intuição intelectual não é uma visão mágica de um saber metafísico aos moldes de um saber empírico, é o modo de ver a dualidade a partir da perspectiva maior da identidade original, um ponto de vista que abrange a racionalidade de fundo que situa as diferenças e a cisão ideal-real. É uma intuição realmente fundante, porque empresta realidade ao objeto; e é o caráter distintivo da razão, que pensa a totalidade e o fundamento. Reflexão é o modo abstrato de ver a totalidade cindida, com vistas à compreensão didática de sujeito e objeto como independentes. Mas um polo não é senão didaticamente isolado do outro. Porque "esta lida e parte de 
oposições”, a reflexão só é “exteriormente útil” (Schelling, 1997, I, 4, p. 114), uma parte empobrecida do pensamento que lida com a empiria.

Em Filosofia da arte encontramos em ares menos herméticos os resultados finais da filosofia da identidade. O parágrafo dois diz: “Deus, enquanto afirmação infinita de si concebe a si mesmo como infinitamente afirmador, como infinitamente afirmado e como indiferença entre ambos". E no parágrafo seis: "O absoluto em si não é nem consciente nem inconsciente, nem livre nem não livre ou necessário" (Schelling, 1997, I, 5, pp. 374; 377). Estava aberto o flanco para o ataque de Hegel. Com todas as ressalvas já feitas, parecia haver certo recrudescimento do formato monolítico do panteísmo espinosano.

Que isso não fosse verdade e contra todas as acusações de ateísmo e panteísmo crasso é que se dirigiram os escritos da fase da liberdade. Nela Schelling tentará evidenciar não apenas que sua filosofia comporta, mas que sempre esteve à sombra da visão voluntarista cristã.

\section{Da abstração intelectual ao fundo abismal da liberdade}

Em contraste com o cariz homogeneizador da filosofia da identidade, nas Preleções privadas de Stuttgart Schelling dirá:

Quem concebe Deus como identidade vazia não poderá entender essas coisas. A prova da necessidade dessa assumpção reside no princípio fundamental dos opostos. Sem oposição não há vida. No homem e em cada ser em absoluto se passa o mesmo. Também em nós há um racional e um irracional. Cada coisa, para se manifestar, carece de algo que não é ela mesma stricto sensu. (Este resumo é apenas uma constestação do conceito abstrato de Deus como ens realissimum - illimitatissimum... (Schelling, 1997, I, 7, p. 436)

Na transição entre estas fases (entre a filosofia da identidade e as Investigações), quando Jacobi afirma só haver dois sistemas em contradição, o naturalismo e o teísmo, Schelling retruca que estas “meias cabeças” são as responsáveis pelo desgosto crescente com o teísmo, que o tem deteriorado em favor do verdadeiro ateísmo (Jaeschke, 1994, p. 272). Enquanto Jacobi e outros acusam os filósofos a torto e a direito de ateísmo, por eles associarem a ideia de Deus à natureza e ao ser, o ateísmo real cresce justamente na sombra de uma teologia pobre e conceitualmente precária que não pode senão ver em Deus um simulacro antropomórfico.

Ao afirmar uma tal ligação entre ambos os sistemas não entendo naturalismo como relacionado a uma natureza exterior, mas sim o sistema no qual uma natureza é afirmada EM DEUS. Que sem isto nenhum sistema capaz de conciliar consciência, inteligência e vontade livre em Deus seja possível já o demonstrei pelo princípio precedente - fica também provado que o naturalismo é a fundamentação, a pressuposição necessária do teísmo. / Carta de Schelling a Jacobi (Jaeschke, 1994, p. 271). 
O projeto integrador evidentemente almeja alcançar a interdependência original entre teísmo e monismo naturalista. Para isso, como observa Jörg Dierken em relação à organicidade idealista em geral, é necessária a conciliação entre uma transcendência imanente e uma recíproca constituição purista da subjetividade em si mesma, refletindo-se no mundo através do processo de reflexão bem desdobrado por Fichte. Uma e outra função se complementam numa dialética expansiva em que "diferenças externas e reflexividade interna correspondem-se uma à outra" (Dierken \& Korsch, 2004, p. 114). Este modelo é absolutamente necessário, observa Dierken, se queremos evitar que a ipseidade se constitua por regras alheias a ela mesma. Dito de modo mais simples, a interioridade precisa estar dialeticamente urdida à objetividade para que a constituição efetiva da subjetividade não dependa de algo outro. Tanto o conteúdo do conhecimento quanto o objeto da intencionalidade estão já pressupostos nos próprios mecanismos de volição e intelecção, sendo impossível projetar-se uma consciência que não esteja em relação dialética de dependênciafundamento com um mundo (Henrich, 1999, p. 126).

Logo, não é possível que o conflito mais constitutivo da subjetividade, o conflito entre o bem e o mal, seja diluído na totalidade e para ela não represente mais que uma ilusão ou um engano de perspectiva. 0 próprio idealismo falha se nos apresenta apenas um conceito formal de liberdade, pois "o seu conceito real e vivente é que ela seja um patrimônio do bem e do mal" (Schelling, 1997, I, 7, p. 352).

Nas Investigações Schelling avança muito na formulação de uma subjetividade que não é autoconsciência plena em um purismo transcendental, precisando ascender da lama espessa do mundo para a existência empírica e temporal de uma consciência na qual a autoconsciência é seminal, e só então recompor-se como autoconsciência. Isso porque a razão é, sim, a reintegração e identidade primordial da diferença, mas ela é também mais viva e mais real quando reconstitui diferenças objetivas do que quando a identidade já está abstratamente dada. Ademais, como as primeiras páginas do livro deixam claro (Schelling, 1997, I, 7, pp. 337-341), Schelling insiste em que o fatalismo e a diluição da diferença entre Deus e o mundo expressam mais um reducionismo resultante de leitura incompetente de seus críticos do que algo que ele tivesse factualmente pregado. Para encerrar o caso, Schelling declara seu total repúdio ao fatalismo e a qualquer tipo de indiferentismo, cognitivo ou moral. Daí resulta a famosa passagem sobre a cópula entre sujeito e predicado, que corretamente explicada é “compreensível até para uma criança” (Schelling, 1997, I, 7, p. 341).

Portanto, a efetividade do Eu, ainda que transcendentalmente deduzida em abstrato, depende de uma individualidade do eu em concreto. Individualidade que só pode ser empírica, porque o individuar é estar situado num ponto da cadeia temporal. "Consequentemente, o problema da individuação pode ser considerado um problema 
sistemático fundamental do sistema do idealismo transcendental" (Zantwijk, 2000, p. 140).

Schelling passa a relacionar do modo sinonímico objeto (Gegenstand) e resistência (Widerstand), como se apenas o modo de se considerar o existente fosse responsável pela diferença: objeto para o intelecto, resistência para a vontade. "Todo objeto exprime essa força de resistência, seja isso consciente, como no caso da vontade moralmente reflexiva do homem, ou inconsciente, como no caso de uma mera coisa" (Zantwijk, 2000, p. 237). Com isso a vontade deixa de ser algo oposto ao real, para ser fundadora do real. Em todo o real está uma vontade propositiva ou uma resistência à vontade, que no horizonte de inteligibilidade é objeto. 0 que o sujeito é para o objeto é o antecedente de seu ser, aquilo que o coloca e evoca a existir. Mas isso contradiz o que o objeto tem de ser, um autônomo constituído como forma para o saber, o qual pode, só então, ser desejado ou rejeitado. Certamente, então, o paradoxo só se resolve através de um Sujeito absoluto que, de modo incognoscível para nós, mas demandado pela razão, põe e conhece o objeto num mesmo ato.

A migração da identidade abstrata para o personalismo concreto é uma clara guinada rumo a Böhme, à noção de um Ungrund, onde Deus é mistério e decai, na figura de um oposto, em uma forma material alienada de si mesmo (Cooper, 2006, p. 98). Se não fosse assim, e se espírito e matéria pudessem ser de algum modo equacionados de forma pacífica, como insinuado pela filosofia anterior de Schelling, as próprias distinções entre Deus, natureza, mentes e entes seriam diluídas, justificando a dura crítica de Hegel na Fenomenologia do Espírito. A saída de Deus para o mundo precisa, então, ser um ato de criação que mereça o nome, pois a anterior filosofia da identidade falhara em justificar a diferença e distância entre Criador e criatura, em que pese a necessidade igualmente premente de justificar a organicidade de todo o real, que faz os filósofos flertarem com o monismo. Já não se pode falar de um panteísmo ou monismo estáveis, pois a identidade abstrata foi rompida, rasgada em um “nascimento", uma criação e uma separação.

Passam a ser válidas até mesmo as afirmações mais radicais do pensamento böhmiano: “A vontade toma de onde não há nada, ela é senhora e conquistadora, e não é um ser, mas impera sobre o ser, e o ser só a faz ansiar, como é peculiar ao ser” (Böhme, 1923, p. 325). Nesta imanência do transcendente não há uma criação ex nihilo, mas um encontro entre uma essência potencial e um manifestar atual de si mesmo. Como polos de um par dialético, o indeterminado da liberdade, que nos escapa à definição, é a fonte das concreções possíveis, do que é definido, enquanto as coisas e princípios definidos não têm em si o seu próprio ser, mas sim na liberdade, da qual emergem. 


\section{Conclusão}

Superando o monismo anterior em favor de uma dinâmica cósmica mais conflitiva, Schelling elabora, entre o desfecho da filosofia da identidade e os estudos sobre mitologia, um novo cenário no qual um Deus agente precisa, enquanto sujeito, de um oposto. As Investigações formam o epítome dessa virada. Mais do que um oposto cognitivo, contudo, o novo contraposto carece das mesmas forças volitivas do original, sem o que o antagonismo soaria falso. Na medida em que Deus é, agora, uma vida e uma força, inteiramente ativo, moral e espontâneo, seu oposto precisa se configurar dramaticamente, como algo igualmente vivo. Da queda de braço entre Deus e o mal, assim, redunda a plausibilidade do esforço e empenho do primeiro na produção e direção do mundo. É só através desse esforço, mais compreensível no mito do que na filosofia de cariz conceitual, que Deus se nos revela como pessoa (Zeltner, 1975).

Dale Snow enfatiza que o desenvolvimento da liberdade nas Investigações, cujo objetivo indubitavelmente é apresentar uma gênese concreta para o mal e, com isso, separar as criaturas de Deus, “torna solúvel a unidade em Deus indissolúvel entre subjetivo e objetivo" (Snow, 2000, pp. 323-324). A possibilidade, melhor, a condição factual de crise entre o intelectivo vivente e o material objetivo justifica a crise universalmente evidente do homem enquanto um ser em conflito fáustico consigo mesmo. Ao lançar um fundo para fora de si, o abismo infundado divino dá espaço a um desenvolvimento semi-independente de si mesmo, o qual é condição necessária de todo o antagonismo real. Esse fundo sombrio e inconsciente do qual emerge o homem, em contraste com a atração de Deus que, como um centro do ser, arranca-o da periferia do fundo para a luz e a indeterminação abismais, é o par dialético que faz de todo o ser um nascido, e ser nascido significa emergir da obscuridade e da ignorância rumo à reintegração racional do ser.

A distinção binária entre o bem e o mal, da qual depende a concepção séria de liberdade no entender de Schelling, passa a ser possível e logicamente coerente com o projeto filosófico, que não mais relativiza essa oposição através de um monismo plácido e indiferente.

\section{Referências}

Baader, F. von. (1855). Sämmtliche Werke: Vorlesungen und Erläuterungen über J. Böhme's Lehre. Leipzig: Hermann Bethman.

Böhme, J. (1842). Jakob Böhmes Sämmtliche Werke. Leipzig: Ambrosius Barth. . (1923). Schriften Jakob Böhmes. Kanser, H. (org.). Leipzig: Im Insel.

Boutroux. M. E. (1908). Études D'Histoire de la Philosophie. Paris: Félix Alcan.

Coelho, H. S. (2012). Livre-arbítrio e sistema; Conflitos e conciliações em Böhme e 
Goethe. Juiz de Fora: UFJF. Tese de doutorado defendida na Universidade Federal de Juiz de Fora. Programa de Pós-graduação em Ciência da Religião.

Cooper, J. (2006). Panentheism. The Other God of the Philosophers. Michigan: Baker Academic.

Copleston, F.C. (1946). Pantheism in Spinoza and the German Idealists. Philosophy 21(78), pp. 42-56.

Danz, C.; Jantzen, J. (Hrsg.). (2011). Gott, Natur, Kunst und Geschichte. Schelling zwischen Identitätsphilosophie und Freiheitsschrift. Wien: Vienna University Press.

Dierken, J. \& Korsch, D. (2004). Subjektivität im Kontext: Erkundungen im Gespräch mit Dieter Henrich. Tübingen: Mohr Siebeck.

Eschenmayer, C. A. (2016). Einleitung in Natur und Geschichte. Bibliothek 1800: Körper - Geist - Bewusstsein. Cristiana Seningaglia (Hrsg.) Stuttgart - Bad Cannstatt: Fromman-holzboog.

Hayner, C. P. (1967). Reason and Existence. Schelling's Philosophy of History. Leiden: Brill.

Henrich, D. (1999). Bewusstes Leben. Stuttgart: Reclam.

Hofmann, P. (2001). Goethes Theologie. Paderborn: Schöningh.

Jaeschke, W. (1994). Religionsphilosophie und spekulative Theologie: Der Streit um die Göttlichen Dinge. (1799-1812). Quellenband. Hamburg: Felix Meiner Verlag.

Martensen, H. L. (1885). Jacob Boehme: His Life and Teaching; or Studies in Theosophy. London: Hodder and Stoughton.

Otto, R. (1994). Studien zur Spinozarezeption in Deutschland 18. Jahrhundert. Frankfurt: Peter Lang.

Richards, R. (2002). The Romantic Conception of Life: Science and Philosophy in the Age of Goethe. Chicago and London: Chicago University Press.

Schelling, F. W. J. von. (1997). Sämmtliche Werke. CD-ROM: Total Verlag.

Snow, D. E. (2000). The Evolution of Schelling's Concept of Freedom. In: Asmuth, C.; Denker, A.; Vater, M. Schelling. Zwischen Fichte und Hegel. Bochumer Studien zur Philosophie 32. Amsterdam: Grüner.

Timm, H. (1974). Gott und die Freiheit : Studien zur Religionsphilosophie der Goethezeit, Bd. 1, Die Spinozarenaissance. Frankfurt: Klostermann.

Vetö, M. (1998). De Kant à Schelling: Les deux voies de l'Idéalisme allemand. Grenoble: Jerôme Millon.

Zeltner, H. (1975). Das Identitätssystem - und was dann? In: Henrich, D. (Hrsg.) Ist systematische Philosophie möglich? Hegel-Studien 17. Bonn: Bouvier Verlag.

Zantwijk, T. van. (2000). Pan-Personalismus. Schellings transzendentale Hermeneutik der menschlichen Freiheit. Spekulation und Erfahrung 43. Suttgart - Bad Cannstatt: Froomann-holzboog. 